\title{
Antibacterial activity of silver nanoparticles: sensitivity of different Salmonella serovars
}

\section{Carmen Losasso' , Simone Belluco' , Veronica Cibin' ${ }^{1}$, Paola Zavagnin ${ }^{1}$, Ivan Mičetić ${ }^{2}$, Federica Gallocchio ${ }^{1}$, Michela Zanella ${ }^{2}$, Lisa Bregoli ${ }^{2}$, Giancarlo Biancotto ${ }^{1}$ and Antonia Ricci ${ }^{1}$ *}

Department of Food Safety, Istituto Zooprofilattico Sperimentale delle Venezie, Legnaro, Italy

${ }^{2}$ European Center for the Sustainable Impact of Nanotechnology, Veneto Nanotech S.C.p.A., Rovigo, Italy

\section{Edited by: \\ Helen Zgurskaya, University of \\ Oklahoma, USA}

\section{Reviewed by:}

Christopher Rensing, University of

Copenhagen, Denmark

Kunihiko Nishino, Osaka University, Japan

\section{*Correspondence:}

Antonia Ricci, Department of Food Safety, Istituto Zooprofilattico

Sperimentale delle Venezie, viale dell'Università 10, 35020 Legnaro,

Province of Padua, Italy

e-mail: aricci@izsvenezie.it
Salmonella spp. is one of the main causes of foodborne illnesses in humans worldwide. Consequently, great interest exists in reducing its impact on human health by lowering its prevalence in the food chain. Antimicrobial formulations in the form of nanoparticles exert bactericidal action due to their enhanced reactivity resultant from their high surface/volume ratio. Silver nanoparticles (AgNPs) are known to be highly toxic to Gram-negative and Gram-positive microorganisms, including multidrug resistant bacteria. However, few data concerning their success against different Salmonella serovars are available. Aims of the present study were to test the antimicrobial effectiveness of AgNPs, against Salmonella Enteritidis, Hadar, and Senftenberg, and to investigate the causes of their different survival abilities from a molecular point of view. Results showed an immediate, time-limited and serovar-dependent reduction of bacterial viability. In the case of $S$. Senftenberg, the reduction in numbers was observed for up to $4 \mathrm{~h}$ of incubation in the presence of $200 \mathrm{mg} / \mathrm{l}$ of AgNPs; on the contrary, $S$. Enteritidis and $S$. Hadar resulted to be inhibited for up to $48 \mathrm{~h}$. Reverse transcription and polymerase chain reaction experiments demonstrated the constitutive expression of the plasmidic silver resistance determinant (SilB) by $S$. Senftenberg, thus suggesting the importance of a cautious use of AgNPs.

Keywords: Salmonella, antimicrobials, silver resistance, nanoparticles, silver

\section{INTRODUCTION}

Salmonella spp. is recognized as one of the main causes of foodborne illnesses in humans worldwide. In 2011, a total of 95,548 confirmed cases of human salmonellosis were reported in the EU. Moreover, this microorganism is responsible for the largest number of reported European food-borne outbreaks (26.6\% of all outbreaks; EFSA and ECDC, 2013). Two species belong to the genus Salmonella: enterica and bongori. S. enterica includes six subspecies and more than 2500 serovars, based on the Kauffmann-White Le Minor scheme (Grimont and Weill, 2007), with different features in terms of resistance, infectivity, morbidity, and mortality. Even though Salmonella Enteritidis and Typhimurium are the two most frequently isolated serovars among humans (Foley et al., 2011), any serovar is considered capable of causing gastrointestinal illness of varying severity in humans.

Following these considerations, Salmonella nowadays represents a major challenge in animal health and food safety (EFSA and ECDC, 2013); consequently great interest exists in reducing its impact in human health by lowering its prevalence in the food chain through a farm to fork approach. Different control measures have proven to be effective against Salmonella at farm level, such as vaccination and proper hygiene management, whereas the use of antimicrobials is forbidden according to EU Regulation 1177/2006, due to the risk of spread of antimicrobial resistance (COMMISSION REGULATION (EC) No 1177/2006 of 1 August 2006, 2005).
Even though EU Regulations on Salmonella control at farm level focus the attention on a limited number of serovars, Regulation EC 2073/2005 on microbiological criteria for foodstuffs (COMMISSION REGULATION (EC) No 2073/2005 of 15 November 2005 on microbiological criteria for foodstuffs, 2006) compels food business operators to ensure the absence of Salmonella spp. in some foods of animal origin. In cases of non-compliance with the food safety criteria set out in the Regulation, the products shall be withdrawn or recalled, which naturally poses serious problems for food producers.

For these reasons, it is interesting to investigate the efficacy and applicability of new types of safe and effective biocidal compounds. Silver has been used for centuries as an antimicrobial (Silver et al., 2006) to fight infections and prevent spoilage (Rai et al., 2009), and it is well known that silver ions and silver-based compounds are highly toxic to Gram-negative and Gram-positive microorganisms (Bae etal., 2010; Fayaz etal., 2010; You et al., 2011; Maillard and Hartemann, 2012). Previous studies have shown that antimicrobial formulations in the form of nanoparticles (NPs) could be used as effective bactericidal materials due to their enhanced reactivity, resulting from their high surface/volume ratio (Pal et al., 2007; Choi et al., 2008; Park et al., 2009). Particularly, silver in the form of NP (AgNP) is known to exhibit strong biocidal effects on different bacterial species (Sondi and Salopek-Sondi, 2004; Rai et al., 2009), including multidrug resistant bacteria (Lara et al., 2010). It is generally accepted that free silver ions, present or released from the nanomaterials, are able 
to bind cell membrane structures, destabilizing the membrane potential and causing proton leakage (Gogoi et al., 2006; Maillard and Hartemann, 2012). Even though the effectiveness of AgNPs has been tested against the genus Salmonella (Chiao et al., 2012), no data concerning different Salmonella serovars including those which are of the greatest concern to humans, are available to date. Furthermore, the use of silver as an antimicrobial has been found to select resistance determinants (Pelgrift and Friedman, 2013), but little information is available on the possibility that the same effect could also be exerted by AgNPs (Samberg et al., 2011). Moreover, the presence of silver-resistance genes in environmental Salmonella isolates needs to be established (Maillard and Hartemann, 2012) and the resistance to AgNPs of silver resistant bacteria should be confirmed. In fact, NPs have different physiochemical properties, compared to those of bulk material of the same composition, which may possibly result in different toxicity mechanism(s) in biological systems (Nel et al., 2006). The exponential increase in the use of AgNPs in recent years raises some concerns about the risk associated with potential resistance in the bacterial community (Maillard and Hartemann, 2012). Silver resistance in food chain-associated bacteria could be a potential public health problem since silver is a key component in several products (Gupta et al., 1999) specifically devoted to food contact materials. However, data arising from scientific studies on the biological activity of NPs are difficult to interpret due to the peculiar chemical and physical characteristics of these particles. Thus, it is fundamental to provide detailed characterization of any tested NPs, as this would allow the scientific community to compare particles more rationally.

Aims of the present study were to test the antimicrobial effectiveness of silver in the form of NPs (AgNPs) against different Salmonella serovars (Enteritidis, Hadar, Senftenberg) and to investigate the causes of their different survival ability, when identified, from a molecular point of view.

\section{MATERIALS AND METHODS NANOPARTICLES AND CHEMICALS}

Silver nanoparticles suspensions (code NM-300K batch n. 6051) and their control dispersant medium were purchased from LGC Standards (UK). These NPs are included in the Joint Research Center Nanomaterials Repository, are approved within the OECD WPMN (Working Party on Manufactured Nanomaterials) international testing program as selected representative reference nanomaterial (OECD Paris, 2010), and are delivered in aqueous solution containing $4 \%$ of polyoxyethylene glycerol trioleate and polyoxyethylene sorbitan mono-laurate (Tween 20). Silver nitrate $\left(\mathrm{AgNO}_{3}\right)$ was purchased from Sigma-Aldrich (USA).

\section{BACTERIAL STRAINS}

Bacterial wild strains, S. Enteritidis (3546/6 2012) isolated from an environmental swab of a layer hens' pen, S. Hadar (2507/5 2009 ) isolated from a broiler chicken cloacal swab and S. Senftenberg (3014/3 2012) isolated from an environmental swab of a layer hens' pen, were obtained from the collection of pathogenic microorganisms of the OIE Reference Laboratory for Salmonellosis (Istituto Zooprofilattico Sperimentale delle Venezie,
Legnaro, Italy). Salmonella strains were stored in Microbank ${ }^{\mathrm{TM}}$ (Pro-Lab Diagnostics, USA) at $-80^{\circ} \mathrm{C}$ until needed. Klebsiella pneumoniae clone ST258 (García-Fernández et al., 2012), used as positive control, was kindly provided by Dr Alessandra Carattoli at Istituto Superiore di Sanità, Rome, Italy. The stock cultures were subcultured on tryptone agar (TA) slants at $4^{\circ} \mathrm{C}$, and Salmonella serovars were confirmed by serotyping according to Grimont and Weill (2007), transferred to $15 \mathrm{ml}$ of Mueller-Hinton broth (MHB) and incubated at $37^{\circ} \mathrm{C}$ overnight.

\section{ANTIMICROBIAL SUSCEPTIBILITY TESTING}

Salmonella strains were tested for susceptibility to antimicrobials (Table 1) using a commercial microdilution test (Sensititre ${ }^{\circledR}$ Salmonella plate - EUMVS2) according to the manufacturer's recommendations. The results were read visually after $24 \mathrm{~h}$ of incubation at $37^{\circ} \mathrm{C}$, and the minimum inhibitory concentration (MIC) was defined as the lowest concentration of the antimicrobial that completely inhibited visible growth.

\section{AgNPs CHEMICAL PURITY}

Chemical purity of AgNPs was evaluated by inductively coupled plasma mass spectrometry (ICP-MS, NexION 300D PerkinElmer). In order to obtain a suitable concentration for ICP-MS analysis, a diluted solution of AgNPs was prepared (105 mg/kg), then microwave-assisted digestion (Mars5, CEM) was performed on triplicate samples (average weight: $0.200 \mathrm{~g}$ ) according to the method suggested by Klein et al. (2011). Accurate control of contamination was performed by processing four method blanks. A semi-quantitative analysis was carried out to gain a general evaluation of the impurities, and then the most relevant elements were quantified by an external calibration method.

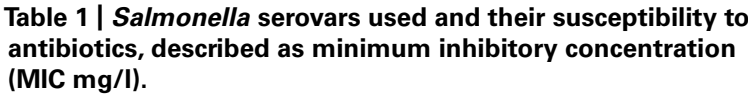
antibiotics, described as minimum inhibitory concentration (MIC mg/l).

\begin{tabular}{llll}
\hline MIC (mg/I) & S. Enteritidis & S. Hadar & S. Senftenberg \\
\hline Sulfamethoxazole & 64 & $>1.024$ & $>1.024$ \\
Gentamicin & 0.50 & 1 & 0.50 \\
Ciprofloxacin & 0.015 & 0.5 & 0.25 \\
Ampicillin & 0.5 & $>32$ & 0.25 \\
Cefotaxime & 0.06 & 0.12 & 0.12 \\
Ceftazidime & 0.25 & 0.50 & 0.25 \\
Tetracycline & 1 & 32 & 1 \\
Streptomycin & 2 & 64 & 16 \\
Trimethoprim & 0.5 & 0.5 & 0.5 \\
Chloramphenicol & 4 & 8 & 8 \\
Colistin & 2 & 2 & 2 \\
Florfenicol & 4 & 4 & 8 \\
Kanamycin & 4 & 4 & 4 \\
Nalidixic acid & 4 & $>64$ & $>64$
\end{tabular}




\section{SIZE AND MORPHOLOGY OF AgNPs}

AgNPs morphology, size and stability over time in the culture medium, were analyzed by transmission electron microscopy (TEM) and dynamic light scattering (DLS). TEM analysis was performed with a Fei Tecnai $12 \mathrm{G} 2$ microscope operated at $120 \mathrm{kV}$. NPs were suspended in ultrapure water at $100 \mathrm{mg} / \mathrm{l}$, deposited on carbon coated copper grids and left to dry overnight. Micrographs were recorded on a side mounted Olympus Morada CCD camera. Size distribution analysis was performed using a semiautomatic method implemented in ImageJ software (Schneider et al., 2012). The analysis involved particle segmentation and area determination. The diameter of each particle was estimated from the particle area assuming a perfectly circular particle. For DLS analyses, AgNPs $50 \mathrm{mg} / \mathrm{l}$ suspension in ultrapure water was analyzed with a Malvern Zetasizer Nano ZS DLS instrument operated in backscattering mode. Measurements were carried out at $23^{\circ} \mathrm{C}$ and were conducted in triplicate to check for sedimentation and solution stability.

\section{AgNPs SUSCEPTIBILITY ASSAY}

The effectiveness of AgNPs as an antimicrobial was determined by assaying the number of culturable bacterial cells which formed colonies after incubation in the presence of $\mathrm{AgNPs}$ or $\mathrm{AgNO}_{3}$. Silver nitrate was used to investigate the effect of silver ions. MHB was used as culture medium with the objective of obtaining a good compromise between Salmonella spp. growth and NPs stability, given that this is a quite simple and non-selective liquid medium, specifically designed for susceptibility studies and having the minimum requirements for bacteria growth.

Briefly, overnight Salmonella inocula, grown in MHB to an OD $\mathrm{A}_{600}=0.3\left[10^{8}\right.$ colony-forming units (CFUs)/ml $]$, were incubated in an orbital shaker at $200 \mathrm{rpm}$ at $37^{\circ} \mathrm{C}$ for $30 \mathrm{~min}, 1,2,4,24,48$, and $72 \mathrm{~h}$ in the presence of AgNPs (200, 150, 100, 50, $20 \mathrm{mg} / \mathrm{l})$ or $\mathrm{AgNO}_{3}(20,15,10 \mathrm{mg} / \mathrm{l})$. Two controls were included: one flask containing NPs and nutrient media devoid of inoculum, and one flask containing inoculum and nutrient media, devoid of NPs or silver nitrate.

The high rotary shaking speed was selected to minimize the aggregation and settlement of the NPs over the incubation period. At the indicated time points ( $30 \mathrm{~min}, 1,2,4,24,48$, and $72 \mathrm{~h}$ ) $100 \mu \mathrm{l}$ aliquots of serial 10-fold dilutions of bacterial cultures in MHB were plated on xylose lysine tergitol 4 (XLT4) agar plates. Colonies were counted after incubation at $37^{\circ} \mathrm{C}$ for $24 \mathrm{~h}$ and counts expressed as CFU/ml. All counts were checked also after $48 \mathrm{~h}$ in order to exclude the presence of colonies possibly sub-lethally injured (but not killed) by AgNPs.

Each of the experiments was performed in triplicate and the CFU counts were normalized and then summarized as mean values and standard deviations (SDs). For statistical purposes a value of 300 colonies was assigned to plates on which more than 300 colonies were observed (according to ISO 7218/2007). The AgNPs and $\mathrm{AgNO}_{3}$ concentrations causing inhibitory effects were determined based on the absence of colonies on the agar plates.

\section{SILVER RESISTANCE MOLECULAR TESTING}

Bacterial total DNA was extracted by boiling extraction method. Briefly, one single colony of each serovar growing on solid media was resuspended in $100 \mu \mathrm{l}$ of sterile molecular biology-grade water (Eppendorf, Hamburg, Germany) in a microcentrifuge tube, subjected to boiling at $100^{\circ} \mathrm{C}$ for $10 \mathrm{~min}$, cooled on ice, and centrifuged at $15,000 \mathrm{~g}$ for $10 \mathrm{~s}$ before being stored at $-20^{\circ} \mathrm{C}$. Total DNA was quantified spectrophotometrically by using a SmartSpec ${ }^{\mathrm{TM}}$ Plus spectrophotometer (Bio-Rad Life Science, USA) and aliquoted.

The plasmidic DNA fraction was extracted from pelleted cells using the QIAprep Spin Miniprep Kit (Qiagen). The concentration and purity of plasmid DNA was determined spectrophotometrically by measuring the $\mathrm{A} 260 \mathrm{~nm} / \mathrm{A} 280 \mathrm{~nm}$ ratio.

\section{REVERSE TRANSCRIPTION AND POLYMERASE CHAIN REACTION}

Overnight $S$. Senftenberg inocula, grown on MHB to an OD $\mathrm{A}_{600}=0.3\left(10^{8} \mathrm{CFU} / \mathrm{ml}\right)$, were incubated in an orbital shaker at $200 \mathrm{rpm}$ at $37^{\circ} \mathrm{C}$ for 4 and $24 \mathrm{~h}$ in the presence of AgNPs $(0$ and $200 \mathrm{mg} / \mathrm{l}$ ) or $\mathrm{AgNO}_{3}$ (0 and $20 \mathrm{mg} / \mathrm{l}$ ). Cell cultures were pelleted and total RNA isolated using the NucliSENS ${ }^{\circledR}$ kit (Biomérieux, Italia SPA). The concentration and purity of RNA was determined spectrophotometrically by measuring the A260nm/A280nm ratio.

For cDNA synthesis, the Enhanced Avian reverse transcription and polymerase chain reaction (RT-PCR) kit (Sigma-Aldrich, USA) was used. Total RNA ( $5 \mu \mathrm{g}$ ) was incubated in DEPCtreated water with $2.5 \mu \mathrm{M}$ oligodT, preheated at $70^{\circ} \mathrm{C}$ for $10 \mathrm{~min}$, and incubated in the presence of avian reverse transcriptase at $42^{\circ} \mathrm{C}$ for $1 \mathrm{~h}$ following the conditions recommended by the manufacturer.

PCR samples were prepared by adding $5 \mu \mathrm{l}$ of $4 \mathrm{ng} / \mu \mathrm{l}$ DNA template to a reaction mix containing $200 \mu \mathrm{M}$ dNTPs, $0.4 \mu \mathrm{M}$ of each primer, $1 \times$ polymerase buffer, $2 \mathrm{mM} \mathrm{MgCl}_{2}$ and $1.5 \mathrm{U}$ of AmpliTaq Gold (Applied Biosystem, USA) DNA polymerase; the reaction volume was made up to $50 \mu \mathrm{l}$ with nuclease-free water. PCRs were carried out in a GeneAmp PCR System 9700 (Applied Biosystem, USA) using the following PCR protocol: $5 \mathrm{~min}$ at $95^{\circ} \mathrm{C}$ followed by 30 cycles of $95^{\circ} \mathrm{C}$ for $30 \mathrm{~s}, 57^{\circ} \mathrm{C}$ for $30 \mathrm{~s}$, and $72^{\circ} \mathrm{C}$ for $30 \mathrm{~s}$. A final elongation step was performed at $72^{\circ} \mathrm{C}$ for $5 \mathrm{~min}$. SilB gene primers sequences, SilB forward (CAAAGAACAGCGCGTGATTA) and SilB reverse (GCTCAGACATTGCTGGCATA), were designed according to Woods et al. (2009).

PCR products were resolved in $1 \%$ agarose Tris acetate-EDTA (TAE) gel, stained with ethidium bromide (Sigma, Dorset, UK), electrophoresed for $1 \mathrm{~h}$ at $70 \mathrm{~V} / \mathrm{cm}$ and visualized with a Bio-Rad Gel doc system. A Perfect DNA Markers (EMD, Millipore, USA), 0.05-10 kb ladder was applied to the gel to define PCR fragment sizes.

\section{RESULTS \\ AgNPs CHARACTERIZATION}

With the use of transmission electron microscope, AgNPs suspension appeared as a mixture of heterogeneous particles by size and shape (Figure 1A). Most particles were spherical, but the sporadic presence of regular polygonal particles was also observed. Particle size distribution (obtained from 8872 particles) showed two major populations, with median ( \pm MAD) diameters of $6( \pm 2)$ and $18( \pm 2) \mathrm{nm}$ (with first and third quartiles at 5-8 and 16-19 nm, respectively; Figure 1B). Particle size distribution 


\section{A}

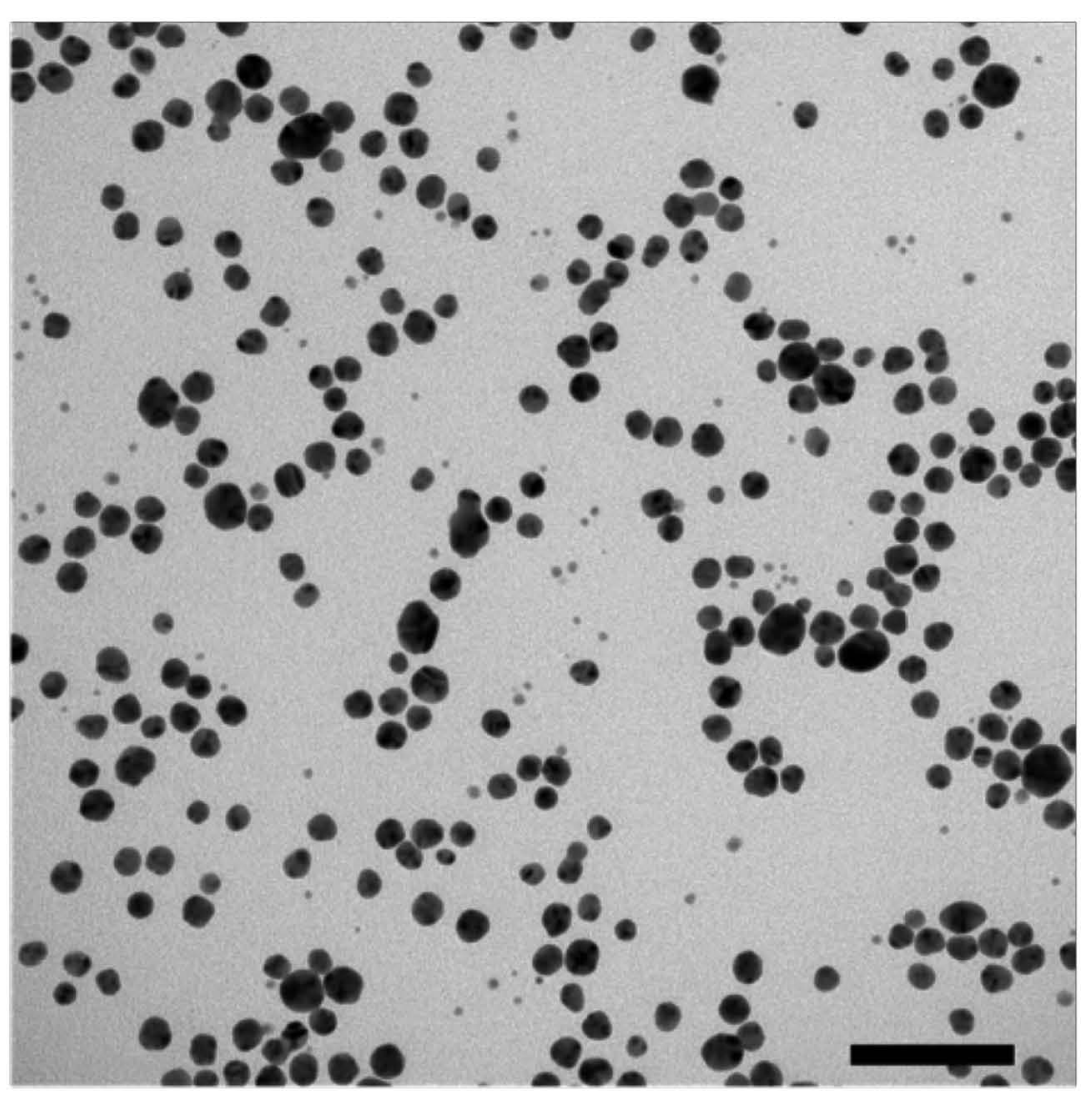

B

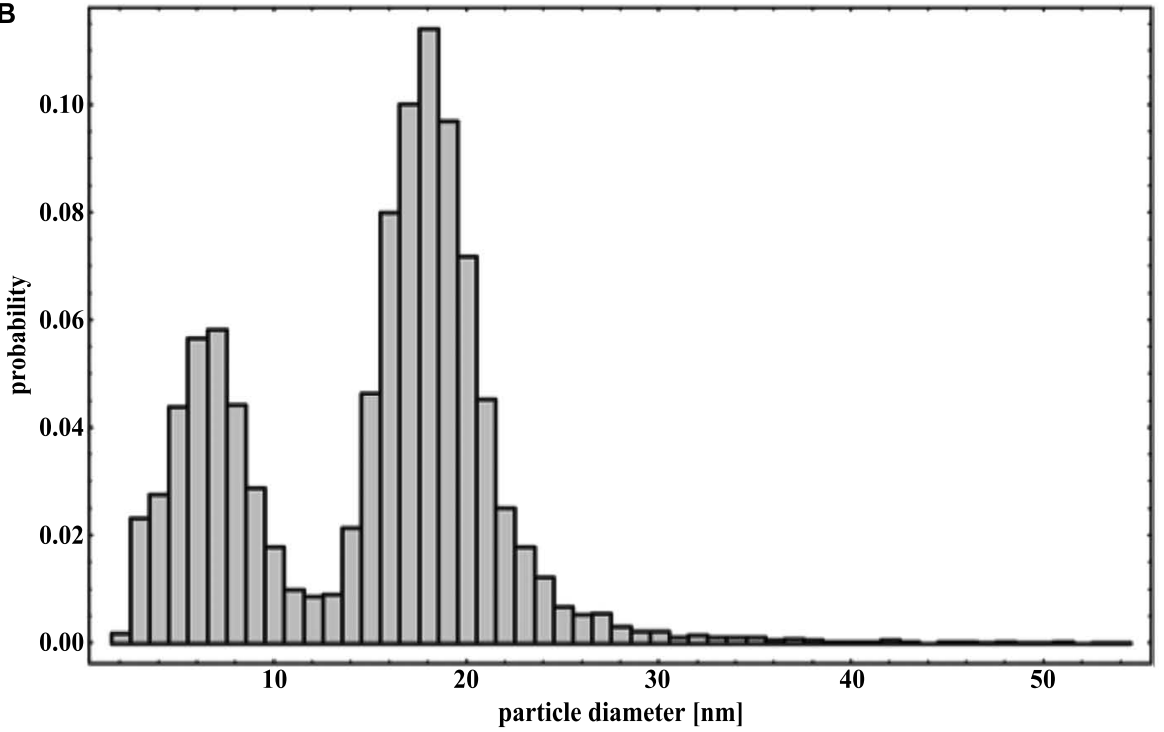

FIGURE 1 | Representative TEM micrograph (A) and particle size distribution obtained from TEM data (B) of NM-300K silver nanoparticles dispersed in water. Scale bar equals $100 \mathrm{~nm}$.

from DLS data agreed with TEM data showing a polydisperse sample $(\mathrm{PDI}=0.485)$ with particles having diameters between 5 and $>500 \mathrm{~nm}$ with the most frequent population having diameters between 6 and $20 \mathrm{~nm}$ (Figure 2). No differences were observed in the AgNPs size and shape after incubation in the presence of the culture medium MHB with no aggregates identified at any time (data not shown).

ICP-MS analysis to evaluate the chemical purity of the AgNPs showed that the contaminant elements ( $\mathrm{V}, \mathrm{Al}, \mathrm{Fe}, \mathrm{Mg}, \mathrm{Si}$ ) detected in the samples were comparable with those in the 


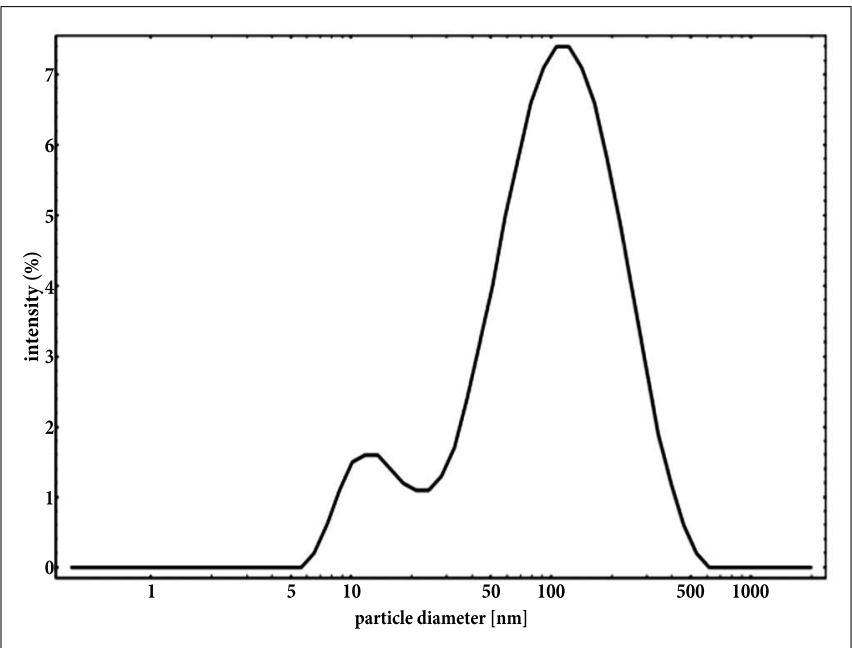

FIGURE 2 | Intensity-based particle size distribution of an aqueous suspension of NM-300K silver nanoparticles obtained from DLS analysis.

blanks. Therefore, these contaminating elements were considered as negligible for the purpose of the present study (data not shown).

\section{Salmonella STRAINS}

Bacterial strains were chosen taking into account their importance for public health, as in the case of $S$. Enteritidis and S. Hadar (EFSA, 2008) and for their ability to adapt to unfavorable chemical-physical environments, as is the case of $S$. Senftenberg (Ng etal., 1969; Broennum Pedersen et al., 2008). Salmonella strains antimicrobial resistances have been described in Table 1.

\section{AgNPs SUSCEPTIBILITY ASSAY}

To compare the antibacterial effect of AgNPs on the Salmonella serovars and to assess the duration of this effect over time, a cell culturability assay in liquid culture was carried out. Equal numbers (approximately $1 \times 10^{8} \mathrm{CFU} / \mathrm{m}$ ) of CFUs of $S$. Enteritidis, $S$. Hadar, and $S$. Senftenberg were incubated individually with different concentrations of AgNPs or $\mathrm{AgNO}_{3}$. At different time points, aliquots were removed and plated onto selective medium to count culturable cells.

As shown in Figure 3, AgNPs treatment reduced Salmonella counts to different extents depending on the serotype. The effect was proportional to the dose with $200 \mathrm{mg} / \mathrm{l}$ being the most effective, and $20 \mathrm{mg} / \mathrm{l}$ the least effective for all tested Salmonella serovars. Moreover, a strong difference in the recovery from the antibacterial effect was observed as $S$. Enteritidis cells never recovered, even after $72 \mathrm{~h}$ of incubation with the maximum AgNPs tested concentration (Figure 3E). S. Hadar clearly displayed a total recovery at $72 \mathrm{~h}$ (Figure $3 \mathrm{C}$ ) while $S$. Senftenberg was inhibited by AgNPs only for $4 \mathrm{~h}$ (Figure 3A). When Salmonella strains were incubated in the presence of the minimum concentration of AgNPs (20 mg/l), their recovery was variable, as AgNPs inhibited $S$. Hadar to a lesser extent than $S$. Enteritidis and $S$. Senftenberg (Figures 3A,C,E).
However, strong differences in the recovery patterns were observed between the three tested serovars. As shown in Figure 3, AgNPs were the most effective against $S$. Enteritidis (Figure 3E), with a noticeable reduction in bacterial numbers after just $1 \mathrm{~h}$ of exposure to a dose of $50 \mathrm{mg} / \mathrm{l}$. In the presence of $100 \mathrm{mg} / \mathrm{l}$ of AgNPs the inhibition continued after $72 \mathrm{~h}$ of exposure. In the case of $S$. Hadar (Figure 3C), although AgNPs displayed effectiveness at the same doses that were effective for $S$. Enteritidis, complete recovery from the antibacterial effects of AgNPs was observed between 1 and $72 \mathrm{~h}$ of exposure, depending on the dose. AgNPs were not effective against $S$. Senftenberg (Figure 3A), which started to grow between 1 and $4 \mathrm{~h}$ of exposure to AgNPs, depending on the dose.

A comparable dose-effect and a parallel trend of reduction in bacterial counts and recovery from the antibacterial effect was observed in the presence of $\mathrm{AgNO}_{3}$ but with one order of magnitude of difference, for each of the tested Salmonella serovars (Figures 3B,D,F).

\section{AgNPs RESISTANCE OF Salmonella STRAINS}

The selective loss of antimicrobial effectiveness, depending on the Salmonella serovar, consented to hypothesize the presence of a specific mechanism of resistance.

To test this hypothesis the three Salmonella serotypes, Senftenberg, Hadar, and Enteritidis, were screened for the presence of the SilB gene, which is one of the most plausible resistant determinants found to be involved in both silver and copper resistance pathway of many Gram-negative bacteria (Silver and Phung, 2005) and can be of either plasmidic or cromosomic origin (Silver, 2003; Silver and Phung, 2005). As shown in Figure 4A, one PCR product of the size of $233 \mathrm{bp}$, expected for SilB fragment amplification, was amplified from total DNA extract only in the case of $S$. Senftenberg (Figure 4A, lane 2). No amplification products were observed in the case of the other investigated Salmonella serovars (Figure 4A, lanes 3 and 4) and this is consistent with the fact that only $S$. Senftenberg showed a silver resistant phenotype in the culturability assay. K. pneumoniae strain, clone ST258, used as positive control (Figure 4A, lane 1), was previously described as carrying the pKPN-IT (JN233704) plasmid, highly related to plasmid pKPN3 identified in K. pneumoniae and conferring resistance to arsenic, copper, and silver (García-Fernández et al., 2012).

To verify the plasmidic origin of the investigated SilB gene, plasmidic DNA was isolated and screened by PCR for the presence of SilB gene. The result, shown in Figure 4B, clearly indicates that the resistance gene was positioned on the plasmidic portion of DNA in the case of $S$. Senftenberg (Figure 4B, lane 2) as it was for $K$. pneumoniae strain, clone ST258, used as positive control (Figure 4B, lane 1).

In order to test the expression of SilB gene in the resistant $S$. Senftenberg strain, in presence and absence of $\mathrm{AgNPs}$ or $\mathrm{AgNO}_{3}$, qualitative RT-PCR experiments from total RNA extract were carried out. K. pneumoniae strain, clone ST258, was used as control. As indicated in Figure 5, SilB is constitutively expressed by $S$. Senftenberg strain both in the presence of AgNPs or $\mathrm{AgNO}_{3}$ and in the absence of any silver forms with $K$. pneumoniae strain displaying the same expression profile (Figure 5). 


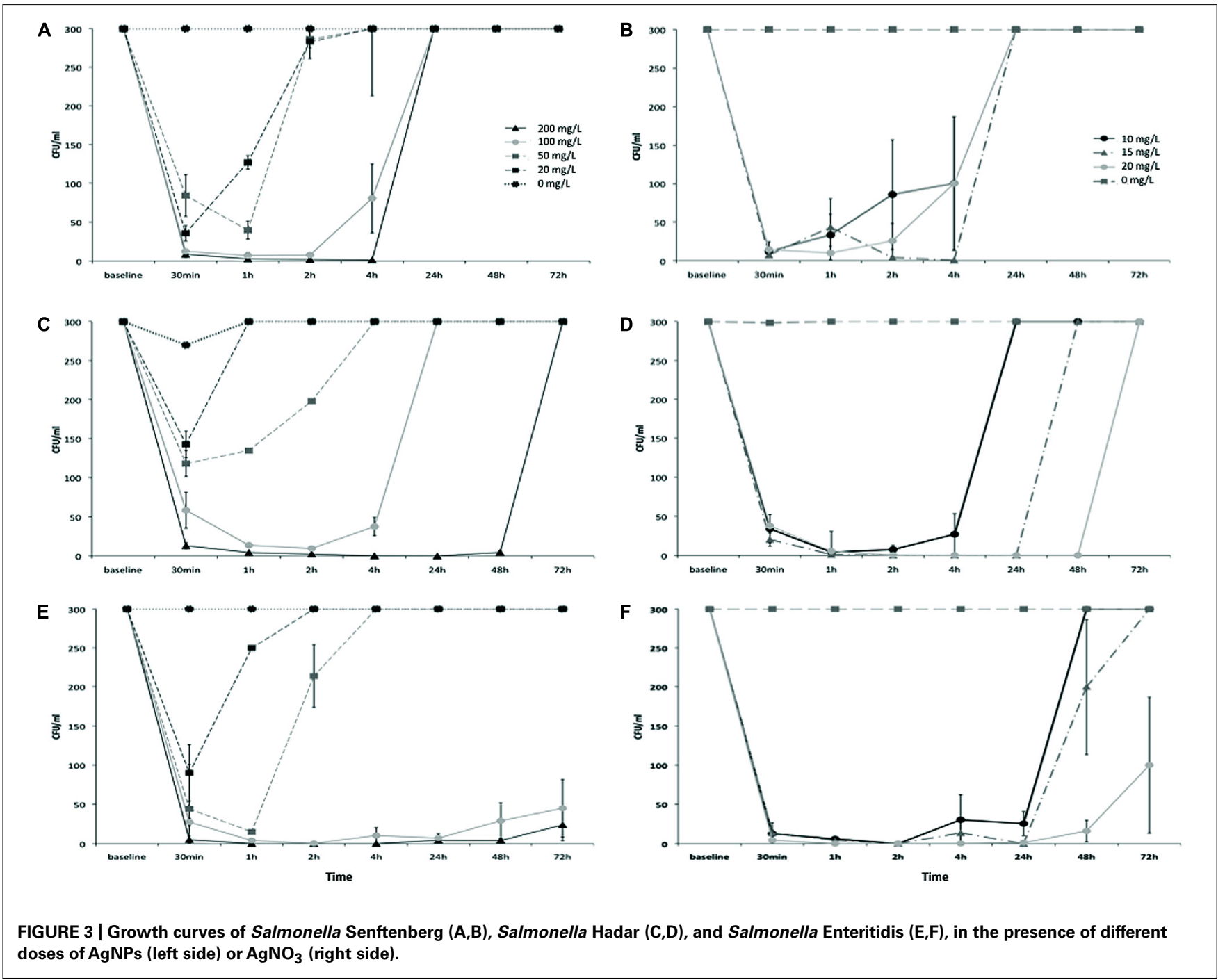

\section{DISCUSSION}

The continued evolution of bacteria strains displaying resistance to multiple antibiotics, has prompted the scientific community as well as the food business operators to look for antimicrobial alternatives. Thus silver, which is commonly considered a broad-spectrum antimicrobial agent, could represent a suitable option, especially in its nanoform (Silver et al., 2006). There is circumstantial evidence that these particles have good antimicrobial activity; however, the exact way in which they exert this activity is still speculative (Pelgrift and Friedman, 2013). AgNPs have shown antimicrobial activity against a wide array of microbes, probably due to their multiple mechanisms of antimicrobial action, including activity against drug-resistant bacteria, fungi, and viruses (Sondi and Salopek-Sondi, 2004; Pal et al., 2007; Choi et al., 2008; Fayaz et al., 2010; Lara et al., 2010; Samberg et al., 2011; You et al., 2011). Nonetheless the present study demonstrates that AgNPs can be effective as an antimicrobial even in the case of Salmonella, but that its success is strongly Salmonella strain-dependent, since great differences in terms of effective dose and time of action were observed for the three investigated serovars (S. Enteritidis, S. Hadar, and S. Senftenberg). This is probably due to many factors strictly related to the genetic features of each strain, including the presence of specific genetic determinants of resistance, as demonstrated in the case of $S$. Senftenberg, which specifically expressed the resistance gene SilB. The antimicrobial resistances for the tested antibiotics, displayed in Table 1, do not followed the same pattern of silver resistance since $S$. Hadar appeared in general more resistant than $S$. Senftenberg. Silver resistance has been reported in bacteria isolated from both clinical (Carr and Rosenkranz, 1975; Annear et al., 1976; Hendry and Stewart, 1979; Markowitz et al., 1983; Klasen, 2000) and environmental (Belly and Kydd, 1982; Haefeli et al., 1984; Grewal and Tiwari, 1990; Choudhury and Kumar, 1998) settings. The resistance mechanisms include altered cell membranes that decrease uptake of $\mathrm{Ag}$ and efflux pumps that pump Ag out of the cell (Silver and Phung, 2005). Among the determinants of silver resistance, SilB was originally found on Salmonella plasmid pMG101 (Mchugh et al., 1975) and encodes resistances to $\mathrm{Ag}^{+}, \mathrm{Hg}^{2+}$, and tellurite, as well as to several antibiotics (Mchugh et al., 1975; Gupta etal., 1999). Salmonella and 


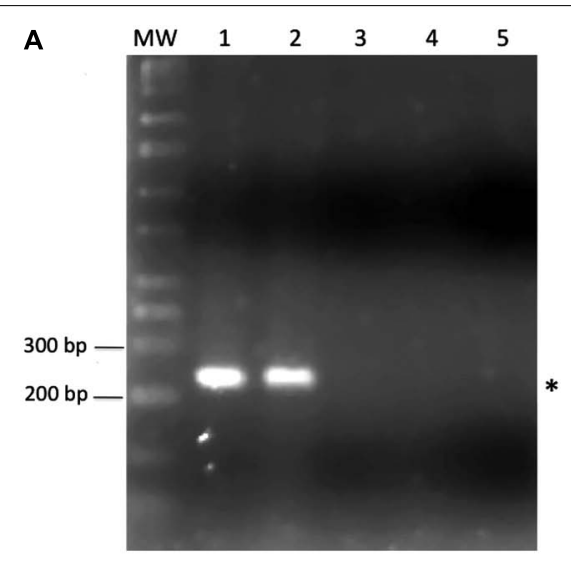

FIGURE 4 | (A) One percent agarose gel showing the PCR product of SilB amplification from total DNA of Klebsiella pneumoniae, clone ST258 (lane 1), Salmonella Senftenberg (lane 2), Salmonella Hadar (lane 3), Salmonella Enteritidis (lane 4). In the lane 5 was run the negative control (DNA template replaced by sterile water). (B) One percent agarose gel showing the PCR

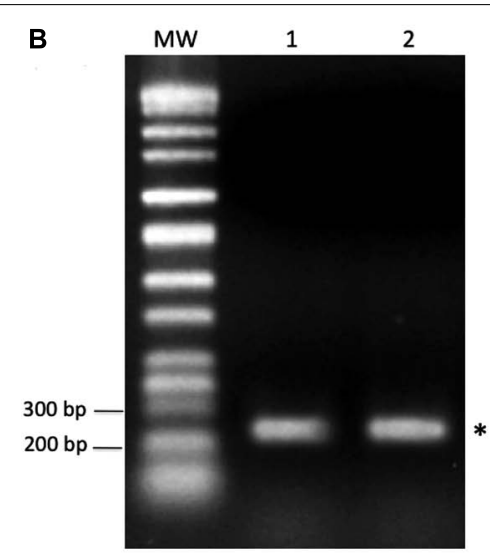

product of SilB amplification from the plasmidic DNA fraction of Klebsiella pneumoniae, clone ST258 (lane 1) and Salmonella Senftenberg (lane 2). The asterisks indicate the $233 \mathrm{bp}$ PCR product expected for SilB fragment amplification. MW indicates the Perfect DNA Markers (EMD, Millipore, USA), 0.05-10 kb ladder.

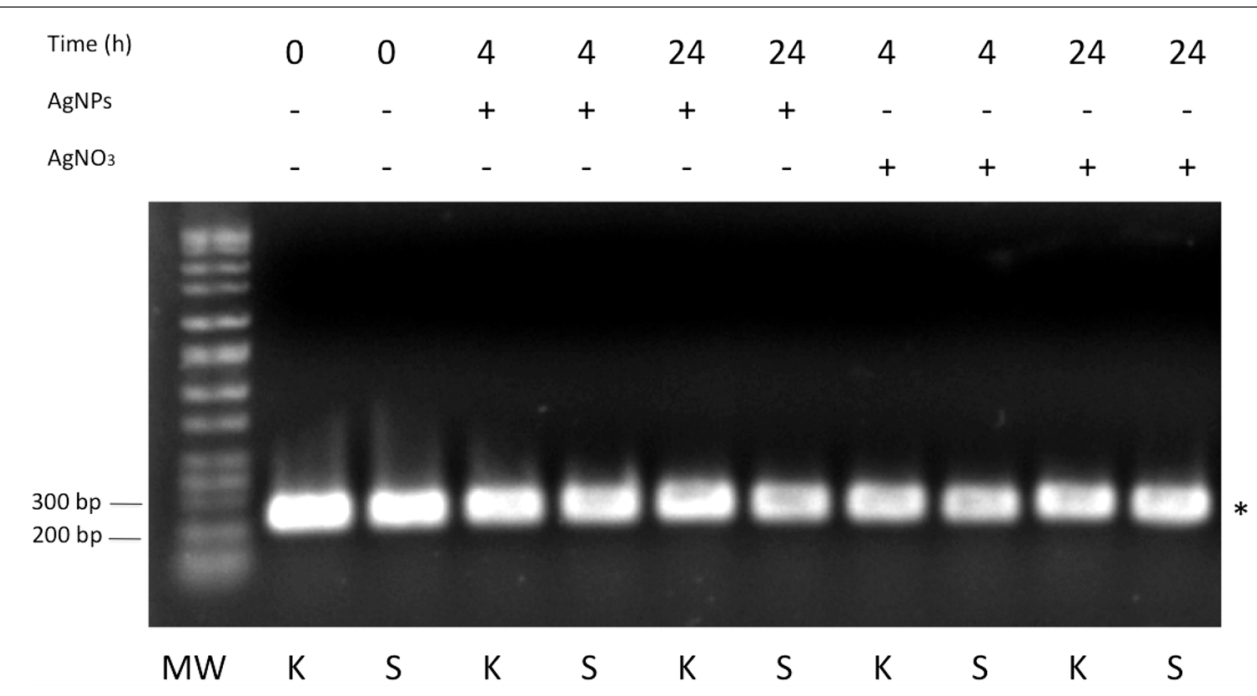

FIGURE 5 | RT-PCR analysis. One percent agarose gel showing DNA bands originating from PCR amplification experiments referring to Klebsiella pneumoniae, clone ST258 (K) and Salmonella Senftenberg (S). The asterisk indicates the $233 \mathrm{bp}$ PCR product expected for SilB fragment amplification. MW indicates the Perfect DNA Markers (EMD, Millipore, USA), 0.05-10 kb ladder.
Escherichia coli have, in addition, a related chromosomal $\mathrm{Ag}^{+}$resistance determinant (Gupta et al., 2001; Franke et al., 2003; Silver, 2003).

However, silver export from Gram-negative bacterial cells might also be determined by other efflux systems, as the Agr and CusCBA protein complexes (Franke et al., 2003) that can bind both copper and silver. Moreover P-type ATPases and cation diffusion facilitators that export surplus metals from the cytoplasm can be involved in metal resistance. These determinants are not only necessary for resistance to toxic metal ions such, but also needed to tolerate at high concentrations some metals that are essential at low concentrations (Nies and Herzberg, 2013) as in the case of Salmonella spp. CopA and GolT, P-type ATPases (Espariz et al., 2007; Pontel et al., 2007; Osman et al., 2010, 2013).
The silver resistance conferred by plasmid pMG101 contains nine genes (Gupta et al., 1999; Silver, 2003) coding for one efflux ATPase (SilP), two metal-binding proteins (SilF and SilE), and one cation/proton antiporter (SilCBA; Gupta et al., 1999; Silver et al., 2006). All these proteins are supposed to work in a synergistic way as SilP release $\mathrm{Ag}^{+}$in the periplasmic space, SilF functions as a $\mathrm{Ag}^{+}$carrier from its periplasmic site of release by SilP to the periplasmic site of uptake by SilA as part of the SilCBA complex, which drives $\mathrm{Ag}^{+}$out from the bacterial cell (Silver et al., 2006). Within the SilCBA complex, SilA is an inner membrane cation pump protein, SilC is an outer membrane protein and SilB is a periplasmic membrane fusion protein that spans the inner and outer membrane and contacts both SilA and SilC (Gupta et al., 1999; Silver et al., 2006). Due to its central role in the unique $\mathrm{Ag}^{+}$ 
external efflux system, SilB could represent a good marker for the presence of the silver resistance pathway. Since silver has a broad range of actions on cellular processes, silver resistance does not seem to spread as antibiotic resistance does, and which, in contrast, specifically targets one process. In spite of this, plasmid-encoded silver resistance is a matter of concern, since plasmid-mediated metallic salt resistance has been associated with co-resistance to chemotherapeutic antibiotics (Mchugh et al., 1975; Gupta et al., 1999), and furthermore, the fact that it is a plasmid-mediated resistance means it has potential to easily spread among the bacterial community, both commensal and pathogenic (Szmolka and Nagy, 2013). In addition, silver resistance might persist in the clinical setting (Gupta et al., 2001) posing serious threats in consideration of the widespread use of silver in hospital devices, environmental surfaces and disinfection products.

Silver-resistance genes have been assumed to be expressed in response to long-term exposure to Ag, while expression should be lost in the absence of Ag (Lara et al., 2010; Knetsch and Koole, 2011). This could suggest a decrease of evolutionary fitness in bacteria carrying silver resistance genes, due to the genes being permanently carried and copied, but expressed only in the presence of Ag (Pelgrift and Friedman, 2013). However, gene expression experiments reported in this study clearly demonstrated the constitutive expression of SilB gene, both in the presence and in the absence of silver, in both its tested forms: "nano" or ionic. Moreover, $S$. Senftenberg tested in this study was isolated from samples belonging to the food chain where silver is not common as contaminant and only trace levels are expected to be present (Millour et al., 2012).

\section{CONCLUSION}

The results obtained from the AgNPs susceptibility assays demonstrate that AgNPs were effective as antibacterial against all treated Salmonella strains only over a short period of time, thus suggesting that the pathogen's ability to survive in the presence of AgNPs could be a challenge for the proposed application.

Moreover the presence of the plasmid containing the SilB gene in the resistant strain $S$. Senftenberg entails that it could be acquired under environmental selective pressure and transferred to other bacterial species. This is of particular importance in the field of food safety because silver compounds are used to sanitize food production plants in order to eliminate pathogens that are considered to be relevant for public health, as the three investigated Salmonella serovars.

Furthermore, the greater activity of $\mathrm{AgNO}_{3}$ compared to that of AgNPs suggests that ions are the more effective elements exerting antibacterial activity. However, further evidence is needed to support this hypothesis.

Nevertheless, it is important to emphasize that the present study took into consideration only one type of AgNP; thus the results here discussed cannot be completely generalized due to the broad variability of NP biological activities that depend not only on their chemical form but also on the specific shape and dimensional range. Smaller sized AgNPs $(<10 \mathrm{~nm})$ were demonstrated to have higher antimicrobial activity than larger particles (Xu et al., 2004; Gogoi et al., 2006). In addition, Pal et al. (2007), demonstrated that triangular shaped particles of silver were more active as antimicrobials than rods and spherical particles (Pal et al., 2007) and in a study by Lok et al. (2007) oxidized particles were shown to exert different antimicrobial properties (Lok et al., 2007). This indicates that the surface area of the particles is important for their activity, as $\mathrm{Ag}^{+}$release, the determining factor for antimicrobial activity, might be dependent on the surface area. Therefore, the inhibitory or antibacterial effects AgNPs have on Salmonella must be evaluated a case-by-case basis in the future.

\section{ACKNOWLEDGMENTS}

The authors wish to acknowledge Alessandra Longo and Elena Ramon of the Biofood platform, Istituto Zooprofilattico Sperimentale delle Venezie, for their technical support. This work was supported by the Ministry of Health, IT (project code RC IZSVe 01/11).

\section{REFERENCES}

Annear, D., Mee, B., and Bailey, M. (1976). Instability and linkage of silver resistance, lactose fermentation, and colony structure in Enterobacter cloacae from burn wounds. J. Clin. Pathol. 29, 441-443. doi: 10.1136/jcp.29.5.441

Bae, E., Park, H. J., Lee, J., Kim, Y., Yoon, J., Park, K., et al. (2010). Bacterial cytotoxicity of the silver nanoparticle related to physicochemical metrics and agglomeration properties. Environ. Toxicol. Chem. 29, 2154-2160. doi: $10.1002 /$ etc. 278

Belly, R., and Kydd, G. (1982). Silver resistance in microorganisms. Dev. Ind. Microbiol. 23, 567-578.

Broennum Pedersen, T., Elmerdahl Olsen, J., and Bisgaard, M. (2008). Persistence of Salmonella Senftenberg in poultry production environments and investigation of its resistance to desiccation. Avian Pathol. 37, 421-427. doi: 10.1080/03079450802216561

Carr, H. S., and Rosenkranz, H. S. (1975). R factor in Enterobacter cloacae resistant to silver sulfadiazine. Chemotherapy 21, 41-44. doi: 10.1159/000221842

Chiao, S., Lin, S., Shen, C., Liao, J., Bau, I., Wei, J., et al. (2012). Efficacy and safety of nanohybrids comprising silver nanoparticles and silicate clay for controlling Salmonella infection. Int. J. Nanomed. 7, 2421. doi: 10.2147/IJN.S31594

Choi, O., Deng, K. K., Kim, N. J., Ross, L. Jr., Surampalli, R. Y., and Hu, Z. (2008). The inhibitory effects of silver nanoparticles, silver ions, and silver chloride colloids on microbial growth. Water Res. 42, 3066-3074. doi: 10.1016/j.watres.2008.02.021

Choudhury, P., and Kumar, R. (1998). Multidrug-and metal-resistant strains of Klebsiella pneumoniae isolated from Penaeus monodon of the coastal waters of deltaic Sundarban. Can. J. Microbiol. 44, 186-189. doi: 10.1139/w97-144

COMMISSION REGULATION (EC) No 1177/2006 of 1 August 2006. (2005). Microbiological criteria for foodstuffs. OJ L 338/1.

COMMISSION REGULATION (EC) No 2073/2005 of 15 November 2005 on microbiological criteria for foodstuffs. (2006). Implementing Regulation (EC) No $2160 / 2003$ of the European Parliament and of the Council as regards requirements for the use of specific control methods in the framework of the national programmes for the control of Salmonella in poultry. OJ L 212/3.

EFSA. (2008). Scientific Opinion of the Panel on Biological Hazards on a request from the European Food Safety Authority on foodborne antimicrobial resistance as a biological hazard. EFSA J. 765, 1-87.

EFSA, and ECDC. (2013). The European Union summary report on trends and sources of zoonoses, zoonotic agents and food-borne outbreaks in 2011. EFSA J. 11, 3129. doi: 10.2903/j.efsa.2013.3129

Espariz, M., Checa, S. K., Audero, M. E., Pontel, L. B., and Soncini, F. C. (2007). Dissecting the Salmonella response to copper. Microbiology 153, 2989-2997. doi: 10.1099/mic.0.2007/006536-0

Fayaz, A. M., Balaji, K., Girilal, M., Yadav, R., Kalaichelvan, P. T., and Venketesan, R. (2010). Biogenic synthesis of silver nanoparticles and their synergistic effect with antibiotics: a study against Gram-positive and Gram-negative bacteria. Nanomedicine 6, 103-109. doi: 10.1016/j.nano.2009.04.006

Foley, S. L., Nayak, R., Hanning, I. B., Johnson, T. J., Han, J., and Ricke, S. C. (2011). Population dynamics of Salmonella enterica serotypes in commercial egg and poultry production. Appl. Environ. Microbiol. 77, 4273-4279. doi: 10.1128/AEM.00598-11 
Franke, S., Grass, G., Rensing, C., and Nies, D. H. (2003). Molecular analysis of the copper-transporting efflux system CusCFBA of Escherichia coli. J. Bacteriol. 185, 3804-3812. doi: 10.1128/JB.185.13.3804-3812.2003

García-Fernández, A., Villa, L., Carta, C., Venditti, C., Giordano, A., Venditti, M., et al. (2012). Klebsiella pneumoniae ST258 producing KPC-3 identified in Italy carries novel plasmids and OmpK36/OmpK35 porin variants. Antimicrob. Agents Chemother. 56, 2143-2145. doi: 10.1128/AAC.05308-11

Gogoi, S. K., Gopinath, P., Paul, A., Ramesh, A., Ghosh, S. S., and Chattopadhyay, A. (2006). Green fluorescent protein-expressing Escherichia coli as a model system for investigating the antimicrobial activities of silver nanoparticles. Langmuir 22, 9322-9328. doi: 10.1021/la060661v

Grewal, J., and Tiwari, R. (1990). Resistance to metal ions and antibiotics in Escherichia coli isolated from foodstuffs. J. Med. Microbiol. 32, 223-226. doi: 10.1099/00222615-32-4-223

Grimont, P. A., and Weill, F. (2007). Antigenic Formulae of the Salmonella Serovars Paris: WHO Collaborating Centre for Reference and Research on Salmonella Institut Pasteur.

Gupta, A., Matsui, K., Lo, J., and Silver, S. (1999). Molecular basis for resistance to silver cations in Salmonella. Nat. Med. 5, 183-188. doi: 10.1038/5545

Gupta, A., Phung, L. T., Taylor, D. E., and Silver, S. (2001). Diversity of silver resistance genes in IncH incompatibility group plasmids. Microbiology 147, 3393 3402.

Haefeli, C., Franklin, C., and Hardy, K. (1984). Plasmid-determined silver resistance in Pseudomonas stutzeri isolated from a silver mine. J. Bacteriol. 158, 389-392.

Hendry, A., and Stewart, I. (1979). Silver-resistant Enterobacteriaceae from hospital patients. Can. J. Microbiol. 25, 915-921. doi: 10.1139/m79-136

Klasen, H. (2000). A historical review of the use of silver in the treatment of burns. II. Renewed interest for silver. Burns 26, 131-138. doi: 10.1016/S03054179(99)00116-3

Klein, C., Comero, S., Stahlmecke, B., Romazanov, J., Kuhlbusch, T., Van Doren, E., et al. (2011). NM-Series of Representative Manufactured Nanomateri als: NM-300 Silver Characterisation, Stability, Homogeneity. EUR 24693 EN-2011. Luxembourg: Publications Office of the European Union.

Knetsch, M. L., and Koole, L. H. (2011). New strategies in the development of antimicrobial coatings: the example of increasing usage of silver and silver nanoparticles. Polymers 3, 340-366. doi: 10.3390/polym3010340

Lara, H. H., Ayala-Núnez, N. V., del Carmen Ixtepan Turrent, L., and Padilla, C. R. (2010). Bactericidal effect of silver nanoparticles against multidrug-resistant bacteria. World J. Microbiol. Biotechnol. 26, 615-621. doi: 10.1007/s11274-0090211-3

Lok, C., Ho, C., Chen, R., He, Q., Yu, W., Sun, H., et al. (2007). Silver nanoparticles: partial oxidation and antibacterial activities. J. Biol. Inorg. Chem. 12, 527-534. doi: 10.1007/s00775-007-0208-Z

Maillard, J., and Hartemann, P. (2012). Silver as an antimicrobial: facts and gaps in knowledge. Crit. Rev. Microbiol. 39, 373-383. doi: 10.3109/1040841X.2012.713323

Markowitz, S. M., Smith, S. M., and Williams, D. S. (1983). Retrospective analysis of plasmid patterns in a study of burn unit outbreaks of infection due to Enterobacter cloacae. J. Infect. Dis. 148, 18-23. doi: 10.1093/infdis/148.1.18

Mchugh, G. L., Moellering, R., Hopkins, C., and Swartz, M. (1975). Salmonella typhimurium resistant to silver nitrate, chloramphenicol, and ampicillin. Lancet 1, 235-240. doi: 10.1016/S0140-6736(75)91138-1

Millour, S., Noël, L., Chekri, R., Vastel, C., Kadar, A., Sirot, V., et al. (2012). Strontium, silver, tin, iron, tellurium, gallium, germanium, barium and vanadium levels in foodstuffs from the Second French Total Diet Study. J. Food Compost. Anal. 25, 108-129. doi: 10.1016/j.jfca.2011.10.004

Nel, A., Xia, T., Mädler, L., and Li, N. (2006). Toxic potential of materials at the nanolevel. Science 311, 622-627. doi: 10.1126/science.1114397

Ng, H., Bayne, H. G., and Garibaldi, J. A. (1969). Heat resistance of Salmonella: the uniqueness of Salmonella Senftenberg 775W. Appl. Microbiol. 17, 78-82.

Nies, D. H., and Herzberg, M. (2013). A fresh view of the cell biology of copper in enterobacteria. Mol. Microbiol. 87, 447-454. doi: 10.1111/mmi.12123

OECD Paris. (2010). ENV-JM-MONO (2010) 20-ENG-Guidance Manual for Sponsors.

Osman, D., Patterson, C., Bailey, K., Fisher, K., Robinson, N. J., Rigby, S. E. J., et al (2013). The copper supply pathway to a Salmonella $\mathrm{Cu}, \mathrm{Zn}$-superoxide dismutase involves P1B-type ATPase copper-efflux and periplasmic CueP. Mol. Microbiol. 87, 466-467. doi: $10.1111 / \mathrm{mmi} .12107$
Osman, D., Waldron, K. J., Denton, H., Taylor, C. M., Grant, A. J., and Mastroeni, P. (2010). Copper homeostasis in Salmonella is atypical and copper-CueP is a major periplasmic metal complex. J. Biol. Chem. 285, 25259-25268. doi: 10.1074/jbc.M110.145953

Pal, S., Tak, Y. K., and Song, J. M. (2007). Does the antibacterial activity of silver nanoparticles depend on the shape of the nanoparticle? A study of the Gramnegative bacterium Escherichia coli. Appl. Environ. Microbiol. 73, 1712-1720. doi: 10.1128/AEM.02218-06

Park, H. J., Kim, J. Y., Kim, J., Lee, J. H., Hahn, J. S., Gu, M. B., et al. (2009). Silverion-mediated reactive oxygen species generation affecting bactericidal activity. Water Res. 43, 1027-1032. doi: 10.1016/j.watres.2008.12.002

Pelgrift, R. Y., and Friedman, A. J. (2013). Nanotechnology as a therapeutic tool to combat microbial resistance. Adv. Drug Deliv. Rev. 65, 1803-1815. doi: 10.1016/j.addr.2013.07.011

Pontel, L. B., Audero M. E., Espariz M., Checa S. K., and Soncini F. C. (2007). GolS controls the response to gold by the hierarchical induction of Salmonella-specific genes that include a CBA efflux-coding operon. Mol. Microbiol. 66, 814-825. doi: 10.1111/j.1365-2958.2007.05963.x

Rai, M., Yadav, A., and Gade, A. (2009). Silver nanoparticles as a new generation of antimicrobials. Biotechnol. Adv. 27, 76-83. doi: 10.1016/j.biotechadv.2008.09.002

Samberg, M. E., Orndorff, P. E., and Monteiro-Riviere, N. A. (2011). Antibacterial efficacy of silver nanoparticles of different sizes, surface conditions and synthesis methods. Nanotoxicology 5, 244-253. doi: 10.3109/17435390.2010.525669

Schneider, C. A., Rasband, W. S., and Eliceiri, K. W. (2012). NIH Image to ImageJ: 25 years of image analysis. Nat. Methods 9, 671-675. doi: 10.1038/nmeth.2089

Silver, S. (2003). Bacterial silver resistance: molecular biology and uses and misuses of silver compounds. FEMS Microbiol. Rev. 27, 341-353. doi: 10.1016/S01686445(03)00047-0

Silver, S., and Phung, L. T. (2005). A bacterial view of the periodic table: genes and proteins for toxic inorganic ions. J. Ind. Microbiol. Biotechnol. 32, 587-605. doi: 10.1007/s10295-005-0019-6

Silver, S., Phung, L. T., and Silver, G. (2006). Silver as biocides in burn and wound dressings and bacterial resistance to silver compounds. J. Ind. Microbiol. Biotechnol. 33, 627-634. doi: 10.1007/s10295-006-0139-7

Sondi, I., and Salopek-Sondi, B. (2004). Silver nanoparticles as antimicrobial agent: a case study on E. coli as a model for Gram-negative bacteria. J. Colloid Interface Sci. 275, 177-182. doi: 10.1016/j.jcis.2004.02.012

Szmolka, A., and Nagy, B. (2013). Multidrug resistant commensal Escherichia coli in animals and its impact for public health. Front. Microbiol. 4:258. doi: 10.3389/fmicb.2013.00258

Woods, E., Cochrane, C., and Percival, S. (2009). Prevalence of silver resistance genes in bacteria isolated from human and horse wounds. Vet. Microbiol. 138, 325-329. doi: 10.1016/j.vetmic.2009.03.023

Xu, X. N., Brownlow, W. J., Kyriacou, S. V., Wan, Q., and Viola, J. J. (2004) Real-time probing of membrane transport in living microbial cells using single nanoparticle optics and living cell imaging. Biochemistry 43, 10400-10413. doi: 10.1021/bi036231a

You, J., Zhang, Y., and Hu, Z. (2011). Bacteria and bacteriophage inactivation by silver and zinc oxide nanoparticles. Colloids Surf. B Biointerfaces 85, 161-167. doi: 10.1016/j.colsurfb.2011.02.023

Conflict of Interest Statement: The authors declare that the research was conducted in the absence of any commercial or financial relationships that could be construed as a potential conflict of interest.

Received: 27 January 2014; accepted: 29 April 2014; published online: 26 May 2014. Citation: Losasso C, Belluco S, Cibin V, Zavagnin P, Mičetić I, Gallocchio F, Zanella M, Bregoli L, Biancotto $G$ and Ricci A (2014) Antibacterial activity of silver nanoparticles: sensitivity of different Salmonella serovars. Front. Microbiol. 5:227. doi: $10.3389 /$ fmicb.2014.00227

This article was submitted to Antimicrobials, Resistance and Chemotherapy, a section of the journal Frontiers in Microbiology.

Copyright (c) 2014 Losasso, Belluco, Cibin, Zavagnin, Mičetić, Gallocchio, Zanella, Bregoli, Biancotto and Ricci. This is an open-access article distributed under the terms of the Creative Commons Attribution License (CC BY). The use, distribution or reproduction in other forums is permitted, provided the original author(s) or licensor are credited and that the original publication in this journal is cited, in accordance with accepted academic practice. No use, distribution or reproduction is permitted which does not comply with these terms. 